\title{
Amelioration of Acrylamide Induced Neurotoxicity in Wistar Rats
}

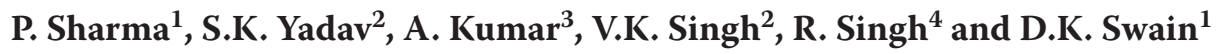 \\ ${ }^{1}$ Sperm Signalling Laboratory, Department of Veterinary Physiology, College of Veterinary Science and Animal Husbandry, U.P. \\ Pandit Deendayal Upadhayaya Pashu Chikitsa Vigyan Vishwavidyalaya Evam Go Anusandhan Sansthan, Mathura, \\ Uttar Pradesh, INDIA \\ ${ }^{2}$ Department of Microbiology and Immunology, College of Veterinary Science and Animal Husbandry, U.P. Pandit Deendayal \\ Upadhayaya Pashu Chikitsa Vigyan Vishwavidyalaya Evam Go Anusandhan Sansthan, Mathura, Uttar Pradesh, INDIA \\ ${ }^{4}$ Department of Veterinary Pathology, College of Veterinary Science and Animal Husbandry, U.P. Pandit Deendayal Upadhayaya \\ Pashu Chikitsa Vigyan Vishwavidyalaya Evam Go Anusandhan Sansthan, Mathura, Uttar Pradesh, INDIA
}

*Corresponding author: P Sharma; E-mail: speak2sharmapiya006@gmail.com

Received: 12 Feb., 2020

Revised: 10 March, 2020

Accepted: 18 March, 2020

\begin{abstract}
Present study was undertaken to study the neurotoxicity of oral acrylamide (ACR) and its amelioration using $\alpha$-tocopherol, reduced glutathione (GSH) and hot aqueous extract (HAE) of Ocimum sanctum. Forty five male Wistar rats were divided into 12 groups. The study showed a significant reduction in the body weight of the rats fed with ACR in comparison to the other groups while body weight was restored in the rats fed with $\alpha$-tocopherol and HAE. Neurotoxicity in rats fed with ACR was evident with the results of histopathology and oxidative stress (high MDA and decreased activities of GSH, SOD, GST and CAT in brain). Co-administration of $\alpha$-tocopherol and HAE lowered these changes however, there was no marked improvement seen in neural damage but improvement was evident in behavioral as well as physiological changes at a marked point. Histopathology of brain in ACR alone fed group showed extensive neural degeneration and massive deposition of fibrin which was substantially decreased and ameliorated with the co-administration of $\alpha$-tocopherol and HAE. These results support the oxidative stress results as well. Our results suggests that $\alpha$-tocopherol and HAE can be useful for protecting brain tissue against ACR induced neurotoxicity through minimizing the free radical mediated oxidative stress.
\end{abstract}

Keywords: Brain, Neurotoxicity, $\alpha$-tocopherol, Acrylamide, Oxidative Stress

Acrylamide or 2-propenamide is a chemical compound with chemical formula $\mathrm{CH}_{2}=\mathrm{CH}-\mathrm{CO}-\mathrm{NH}_{2}$, is a colorless, non-volatile crystalline solid, soluble in water and has a molecular weight of $71.08 \mathrm{kDa}$ that can be produced at high levels in high-carbohydrate heat treated foods The risks of ACR to health and its toxic properties (neurotoxicity, genotoxicity, carcinogenicity and reproductive toxicity) were demonstrated by the Scientific Committee on Toxicity, Ecotoxicity and the Environment in 2001. Potato and bakery products account for around $50 \%$ and $20 \%$ of human exposure to ACR, respectively (Keramat et al., 2011).

Factors affecting ACR formation and degradation in foods are ACR precursors such as free amino acids (mainly asparagine), reducing sugars and processing conditions (i.e. baking time and temperature, moisture content and matrix of product) (Zhang et al., 2005). ACR has been shown potential to affect nervous system and through its intermediate glycidamide, it induces oxidative stress in brain resulting in neural damage in terms of neural degeneration and cell death. ACR induces oxidative stress and affect the cellular redox chain through the generation of reactive oxygen species (ROS) through its active oxidized metabolite glycidamide (Labored, 2010); glycidamide gets conjugated with glutathione (GSH) leading to lowering of GSH (Chen et al., 2014). ACR has been established as

How to cite this article: Sharma, P., Yadav, S.K., Kumar, A., Singh, V.K., Singh, R. and Swain, D.K. (2020). Amelioration of acrylamide induced neurotoxicity in wistar rats. J. Anim. Res., 10(2): 237-246. 
a proven neurotoxin which targets neuromotor proteins through free radicals and glycidamide and has been seen to affect the neuron functions (Abo-El-Matty et al., 2018).

Extensive studies have been done in recent years showing involvement of ACR in neurotoxicity; however, only few studies have been undertaken using various bioactive agents to study its amelioration. Looking to the potential involvement of ACR in neurotoxicity, and its close association with human life, the present study was undertaken in male Wistar rats to evaluate short term dietary exposure effects of ACR in brain and ameliorative potential of different antioxidants ( $\alpha$-tocopherol, GSH and HAE) which are considered as proven antioxidants protecting the cells from free radical mediated oxidative damage.

\section{MATERIALS AND METHODS}

\section{Ethical permission}

Ethical permission was taken from Institutional Animal Ethics Committee (Approval no. 119/IAEC/18 dated 2302-2018) for carrying out all experimental procedures in male Wistar rats.

\section{Experimental Animals}

Present experiment was conducted in 45 pure bred adult male Wistar rats procured form Central Laboratory Facilities, All India Institute of Medical Sciences, New Delhi. All the rats were given two weeks preexperiment acclimatization period and maintained under Good Management Practices as prescribed by CPCSEA in Small Laboratory Animal House of Department of Veterinary Microbiology, College of Veterinary Sciences and A.H., DUVASU, Mathura, Uttar Pradesh, India during experiment. Animals were maintained with standard feeding practices and were apparently free of infection. After the experiment, all the animals were disposed of as per the approval of IAEC.

\section{Experimental groups}

Forty five adult male Wistar rats weighing between 130$150 \mathrm{~g}$ were divided into 12 groups namely as Group A: ACR alone; Group B: ACR $+\alpha$-tocopherol; Group C:
ACR + HAE; Group D: ACR + GSH; Group E: ACR + $\alpha$-tocopherol + HAE ; Group F: ACR $+\alpha$-tocopherol + GSH; Group G: ACR + HAE + GSH; Group H: ACR+HAE $+\alpha$-tocopherol + GSH; Group I: Basal diet + GSH; Group $\mathrm{J}$ : Basal diet $+\alpha$-tocopherol; and Group K: Negative control (normal diet and water). Each experimental group for ACR toxicity and amelioration was comprised of 4 rats $(n=4)$ and the control groups were having three rats each $(n=3)$. Corn oil group was taken as vehicle control group. $12^{\text {th }}$ group taken as vehicle control group. During the experiment one rat died out of 45 rats from the cornoil group.

\section{Experimental Protocol}

All the animals were maintained with uniform basal diet and were having access to ad lib water. ACR was fed orally using oral gavage having metallic needle (curved ball ended, size PS-16) for 45 days early in the morning before feeding with regular diet. Acrylamide (Sigma, St Louis, USA) was prepared in distilled water and the rats were dosed $30 \mathrm{mg} / \mathrm{Kg} \mathrm{BW}$ in groups; $\alpha$-tocopherol (Sigma, St Louis, USA) was dissolved in corn oil and given $100 \mathrm{mg} / \mathrm{Kg} \mathrm{BW}$, hot aqueous extract of Ocimum sanctum HAE@250mg/Kg BW and reduced glutathione (GSH) (Sigma, St Louis, USA) was dissolved in distilled water and orally given @ 2 mg/Kg BW. The dose of ACR was finalized from the results of the pilot study (data not shown) and doses reported by other groups of researchers (Kahekeshani, 2014; Kumar et al., 2018); $\alpha$-tocopherol as reported earlier from our laboratory (Mandil et al., 2016); and dose of HAE reported and established from our laboratory earlier (Gupta, 2009) and dose of GSH was selected from standard literature as reported (Tredici et al., 1994). Rats of all groups were sacrificed after 45 days of study for the evaluation of histopathological changes in brain and estimation of brain oxidative stress parameters.

\section{General toxicity, body weight and sample collection}

Rats of all groups were closely observed during 45 days of experimental period for any apparent signs of toxicity including discomfort, gait, loss of hair, diarrhoea, mortality, and neurological problems like (circling, noncoordinating movements, poor reflex) and weight loss. All the rats were sacrificed after 45 days of experiment as per guidelines of CPCSEA (Prevention of cruelty to 
animals act, 1960). Body weight of the individual rats was recorded before and after the experimental period of 45 days. During postmortem examination, brain of all rats were collected for the evaluation of oxidative stress parameters, and histopathological examinations, along with this blood samples were collected from retro-orbital sinus region using glass capillary tubes for the evaluation of erythrocyte oxidative indices.

\section{Blood and Brain oxidative stress biomarkers}

Blood from experimental rats was collected on $45^{\text {th }}$ day in heparinised tubes from inner canthus of eye through retro-orbital plexus puncture with the help of glass capillary tubes after overnight fasting. Blood samples were centrifuged at $2000 \mathrm{rpm}$ for $15 \mathrm{~min}$ and plasma was separated. Erythrocytes were separated and stored at $-20^{\circ} \mathrm{C}$ for further analysis of oxidative stress indices (Yagi, 1989). Erythrocytes lysates were made and used for estimation of oxidative stress parameters (GSH, LPO, Catalase, SOD, GST, total protein).

Similar to blood, brain oxidative stress parameters were estimated as previously described for lipid peroxidase (LPO) in terms of malondialdehyde (MDA) production (Shafiq-U-Rehman, 1984); reduced glutathione (GSH) (Sedlak and Lindsay, 1968), Catalase (Bergmeyer, 1983), superoxide dismutase (SOD) (Madesh and Balasubramanian, 1998), glutathione peroxidase (Paglia and Valantine, 1967), glutathione-S-transferase (Habig et al., 1974) and total protein content of tissue homogenate (Lowery et al., 1951).

\section{Histopathological Studies}

A small piece of brain of each rat from the respective groups was collected and stored in $10 \%$ formal saline for histopathological evaluations using $\mathrm{H} \& \mathrm{E}$ stain as per the established method (Luna,1968) and examined to observe the changes in histoarchitecture of brain under 10x, 20x and $40 \mathrm{x}$ objective.

\section{STATISTICAL ANALYSIS}

Statistical analysis was carried out by using the SPSS 16 package (Chicago, USA). Data from different experiments are presented as Mean \pm SEM. Means of the observations were compared by one way analysis of variance (ANOVA) to evaluate the variations and the significance was tested at 0.05 for all the observations. To compare all pair-wise differences in mean, Tukey post hoc test was used and means were considered statistically significant when $(\mathrm{P}<0.05)$.

\section{RESULTS AND DISCUSSION}

\section{Body and organ weight}

Body weights of different groups of rats along with the vehicle control were measured on the day of beginning of the study (0 day) and after completion of study ( $45^{\text {th }}$ day) (Table 1). Body weight of all groups increased till $15^{\text {th }}$ day and after 30 days of study, body weights started declining in Group A to H; however, body weights showed increase trend in control groups of rats (Group I to $\mathrm{K}$ and corn oil vehicle control group). Group B rats showed significant $(\mathrm{P}<0.05)$ improvement in body weight and similar trend was observed in other groups (Group $\mathrm{C}$ to $\mathrm{H}$ ) for body weight. Lowest body weight was found in Group A fed with ACR alone signifying general toxicity of ACR.

Table 1: Body weight (gm) of different groups of rats fed with acrylamide, cornoil and ameliorating agents

\begin{tabular}{cccccc}
\hline $\begin{array}{c}\text { Group of } \\
\text { Rats }\end{array}$ & $\begin{array}{c}\mathbf{0}^{\text {th }} \\
\text { day }\end{array}$ & $\begin{array}{c}\mathbf{1 5}^{\text {th }} \\
\text { Day }\end{array}$ & $\begin{array}{c}\mathbf{3 0}^{\text {th }} \\
\text { Day }\end{array}$ & $\begin{array}{c}\mathbf{4 5}^{\text {th }} \\
\text { Day }\end{array}$ & $\begin{array}{c}\text { \% reduction (-) or } \\
\text { increase }(+) \text { after } \\
\mathbf{4 5}^{\text {th }} \text { of study }\end{array}$ \\
\hline A & 142.5 & 160.5 & 90.5 & 64.12 & -45 \\
B & 145.4 & 158.5 & 130.5 & 105.6 & -27 \\
C & 160.6 & 178.6 & 135.60 & 105.8 & -34 \\
D & 150.6 & 168.5 & 135.6 & 100.6 & -33 \\
E & 170.4 & 190.4 & 140.8 & 110.5 & -35 \\
F & 160.6 & 180.6 & 140.6 & 108.6 & -32 \\
G & 155.5 & 170.8 & 130.5 & 108.5 & -30 \\
H & 146.4 & 160.6 & 120.5 & 102.3 & -30 \\
I & 150.4 & 170.6 & 215.6 & 245.6 & +63 \\
J & 160.3 & 180.6 & 200.4 & 240.3 & +50 \\
K & 150.6 & 170.6 & 225.5 & 270.4 & +79 \\
*Cornoil & 148.4 & 160.6 & 205.6 & 240.5 & +62 \\
Group & 14.4 & & & \\
\hline
\end{tabular}

$\left(0\right.$ day $=$ Day of start of experiment; $45^{\text {th }}$ day $=$ Day of sacrifice of animal) during major study. ${ }^{*}$ Cornoil Group was taken as the vehicle control group.

Analysis of absolute brain weights revealed significant $(\mathrm{P}<0.05)$ reduction in brain weights in Group $\mathrm{A}$ to $\mathrm{K}$ and no 
change in organ weight in Group I to $\mathrm{K}$ and corn oil vehicle control (Table 2). Lowest brain weight was observed in Group A rats indicating ACR mediated brain toxicity. Feeding with $\alpha$-tocopherol and other ameliorating agents significantly $(\mathrm{P}<0.05)$ improved brain weight compared to Group A which was fed with ACR only indicating their ameliorating potential against ACR neurotoxicity.

Table 2: Absolute weights of brain in different groups of rats fed with acrylamide and ameliorating agents

\begin{tabular}{ll}
\hline Different groups of Rats & Brain \\
\hline A & $0.66^{\mathrm{a}} \pm 0.02$ \\
B & $1.12^{\mathrm{c}} \pm 0.14$ \\
C & $0.98^{\mathrm{b}} \pm 0.06$ \\
D & $0.96^{\mathrm{b}} \pm 0.04$ \\
E & $0.88^{\mathrm{b}} \pm 0.06$ \\
F & $0.90^{\mathrm{b}} \pm 0.02$ \\
G & $0.86^{\mathrm{b}} \pm 0.04$ \\
H & $1.06^{\mathrm{c}} \pm 0.06$ \\
I & $1.18^{\mathrm{c}} \pm 0.10$ \\
$\mathrm{~J}$ & $1.28^{\mathrm{c}} \pm 0.12$ \\
K & $1.26^{\mathrm{c}} \pm 0.34$ \\
$*$ Cornoil group $(\mathrm{n}=3)$ & $1.16^{\mathrm{c}} \pm 0.42$ \\
\hline
\end{tabular}

Data are presented as Mean \pm SEM. Different letters above the bar indicates significance $(p<0.05)$ among different groups in the columns. *Cornoil Group was taken as the vehicle control group.

\section{Neurophysiological behavior}

Neurophysiological motor behavior of different groups of rats is illustrated in Table 3. Group A rats fed with ACR alone showed severe non-coordinated movements, circling around their own axis, deviated gait, failure to grip, ataxia, poor reflex to touch and light along with very poor or low cognition indicating ACR induced neural degeneration in cerebral cortex which is the center of motor functions of the body. However, this type of abnormal neurophysiological behavior was not observed in rats of control groups.

Interestingly, administration of $\alpha$-tocopherol with ACR resulted in marked improvement in neurophysiological behavior indicating the active ameliorating potential of $\alpha$-tocopherol from ACR induced neurotoxicity. All the groups of rats receiving GSH, $\alpha$-tocopherol and HAE showed certain degree of improvement in neurophysiological behavior however, the degree of improvement was better and higher in the group B, C and $\mathrm{H}$ receiving different antioxidants.

\section{Oxidative stress parameters in blood}

Table 4 summarizes different oxidative stress parameters evaluated in erythrocytes of different groups of rats. Lipid peroxidase activity was evaluated in different groups of rats fed with acrylamide and antioxidants along with control groups in terms of MDA in erythrocytes. Significant $(\mathrm{P}<0.05)$ increase in level of MDA was observed in Group A compared with other groups (Group B to K). Lowest level of MDA was observed in Group I, J and K (Control groups).

Table 3: Neurophysiological behavior in different groups of rats fed with acrylamide and other ameliorating agents

\begin{tabular}{|c|c|c|c|c|c|c|c|}
\hline $\begin{array}{l}\text { Group of } \\
\text { Rats }\end{array}$ & $\begin{array}{l}\text { Non coordinated } \\
\text { movements }\end{array}$ & $\begin{array}{l}\text { Circling } \\
\text { movement }\end{array}$ & Deviated gait & $\begin{array}{l}\text { Failure to } \\
\text { grip }\end{array}$ & Ataxia & $\begin{array}{l}\text { Poor reflex to } \\
\text { touch and light }\end{array}$ & $\begin{array}{l}\text { Decreased } \\
\text { cognition }\end{array}$ \\
\hline $\bar{A}$ & Severe & Severe & High & Yes & Present & High & Poor/Low \\
\hline B & Absent & Absent & Absent & No & No & Moderate & Good \\
\hline $\mathrm{C}$ & Less & Less & Less & No & No & Moderate & Low \\
\hline $\mathrm{D}$ & Absent & Less & Less & No & No & Moderate & Low \\
\hline $\mathrm{E}$ & Absent & Less & Absent & Yes & No & Moderate & Low \\
\hline $\mathrm{F}$ & Absent & Less & Less & Yes & No & Moderate & Low \\
\hline G & Less & Less & Less & Yes & Yes & Moderate & Low \\
\hline $\mathrm{H}$ & Less & Less & Less & No & Yes & Moderate & Low \\
\hline I & Absent & Absent & Absent & Yes & No & Normal & High \\
\hline $\mathrm{J}$ & Absent & Absent & Absent & Yes & No & Normal & High \\
\hline $\mathrm{K}$ & Absent & Absent & Absent & Yes & No & Normal & High \\
\hline
\end{tabular}


Table 4: Erythrocytes oxidative stress markers in different groups of rats fed with acrylamide and ameliorating agents

\begin{tabular}{|c|c|c|c|c|c|}
\hline Different groups of Rats & LPO & SOD & GSH & GST & CAT \\
\hline $\mathrm{A}$ & $28.80^{c} \pm 4.78$ & $18.68^{\mathrm{a}} \pm 1.14$ & $0.31^{\mathrm{a}} \pm 0.04$ & $23.34^{\mathrm{c}} \pm 1.12$ & $32.34^{\mathrm{a}} \pm 1.1$ \\
\hline $\mathrm{B}$ & $16.46^{\mathrm{b}} \pm 4.32$ & $29.98^{\mathrm{b}} \pm 1.68$ & $0.92^{\mathrm{b}} \pm 0.04$ & $16.56^{\mathrm{b}} \pm 1.26$ & $38.56^{\mathrm{b}} \pm 1.28$ \\
\hline $\mathrm{C}$ & $23.64^{\mathrm{c}} \pm 4.56$ & $20.80^{\mathrm{a}} \pm 1.28$ & $0.44^{\mathrm{a}} \pm 0.06$ & $21.96^{\mathrm{c}} \pm 1.54$ & $31.96^{\mathrm{a}} \pm 1.84$ \\
\hline $\mathrm{D}$ & $22.98^{c} \pm 4.78$ & $22.99^{\mathrm{a}} \pm 1.56$ & $0.39^{\mathrm{a}} \pm 0.02$ & $19.64^{\mathrm{c}} \pm 0.84$ & $32.64^{\mathrm{a}} \pm 1.52$ \\
\hline $\mathrm{E}$ & $23.96^{\mathrm{c}} \pm 2.34$ & $21.16^{\mathrm{a}} \pm 1.86$ & $0.52^{\mathrm{a}} \pm 0.04$ & $18.86^{\mathrm{c}} \pm 1.42$ & $31.66^{\mathrm{a}} \pm 1.54$ \\
\hline $\mathrm{F}$ & $24.36^{\mathrm{c}} \pm 2.86$ & $22.56^{\mathrm{a}} \pm 1.38$ & $0.48^{\mathrm{a}} \pm 0.06$ & $19.2^{\mathrm{c}} \pm 1.14$ & $33.24^{\mathrm{a}} \pm 2.54$ \\
\hline $\mathrm{G}$ & $26.78^{c} \pm 2.69$ & $22.76^{\mathrm{a}} \pm 1.46$ & $0.46^{\mathrm{a}} \pm 0.06$ & $19.06^{\mathrm{c}} \pm 1.28$ & $32.06^{\mathrm{a}} \pm 1.12$ \\
\hline $\mathrm{H}$ & $18.76^{\mathrm{b}} \pm 2.9$ & $27.10^{\mathrm{b}} \pm 1.48$ & $0.68^{b} \pm 0.02$ & $17.66^{\mathrm{b}} \pm 1.84$ & $37.66^{\mathrm{b}} \pm 1.26$ \\
\hline I & $11.64^{\mathrm{a}} \pm 3.1$ & $36.08^{\mathrm{c}} \pm 1.66$ & $1.26^{\mathrm{c}} \pm 0.04$ & $13.96^{\mathrm{a}} \pm 1.52$ & $43.96^{\mathrm{c}} \pm 1.54$ \\
\hline $\mathrm{J}$ & $11.76^{\mathrm{a}} \pm 2.86$ & $36.01^{\mathrm{c}} \pm 1.36$ & $1.28^{\mathrm{c}} \pm 0.06$ & $14.34^{\mathrm{a}} \pm 1.54$ & $44.34^{\mathrm{c}} \pm 0.84$ \\
\hline $\mathrm{K}$ & $10.09^{a} \pm 2.18$ & $36.28^{\mathrm{c}} \pm 1.88$ & $1.29^{\mathrm{c}} \pm 0.08$ & $14.98 \mathrm{a} \pm 1.54$ & $44.98^{\mathrm{c}} \pm 1.42$ \\
\hline$* *$ Cornoil group & $9.10^{\mathrm{a}} \pm 1.18$ & $34.36^{\mathrm{c}} \pm 2.38$ & $1.18^{\mathrm{c}} \pm 0.04$ & $13.64^{\mathrm{a}} \pm 1.16$ & $42.12^{\mathrm{c}} \pm 1.16$ \\
\hline
\end{tabular}

Data are presented as Mean \pm SEM. *LPO (nM MDA/gm of tissue); SOD (U/mg of Protein); GSH (mM GSH/g of Tissue); GST ( $\mu$ M of CDNB-GSH conjugate/min/mg protein); $\mathrm{CAT}\left(\mathrm{mM} \mathrm{H}_{2} \mathrm{O}_{2}\right.$ utilized $/ \mathrm{min} / \mathrm{mg}$ or protein). Different letters above the bar indicates significance $(\mathrm{p}<0.05)$ among different groups in the columns. ${ }^{*}$ Cornoil Group was taken as the vehicle control group.

Table 5: Oxidative stress markers in brain of different groups of rats fed with acrylamide and ameliorating agents

\begin{tabular}{llllll}
\hline Different groups of Rats & LPO & SOD & GSH & GST & CAT \\
\hline A & $312.48^{\mathrm{c}} \pm 5.12$ & $3.78^{\mathrm{a}} \pm 0.14$ & $0.16^{\mathrm{a}} \pm 0.02$ & $0.03^{\mathrm{a}} \pm 0.01$ & $3.28^{\mathrm{a}} \pm 0.14$ \\
B & $210.76^{\mathrm{b}} \pm 3.46$ & $6.66^{\mathrm{c}} \pm 0.68$ & $0.29^{\mathrm{b}} \pm 0.06$ & $0.05^{\mathrm{c}} \pm 0.02$ & $4.24^{\mathrm{b}} \pm 0.18$ \\
$\mathbf{C}$ & $280.76^{\mathrm{c}} \pm 1.168$ & $4.1^{\mathrm{a}} \pm 0.28$ & $0.19^{\mathrm{a}} \pm 0.04$ & $0.04^{\mathrm{a}} \pm 0.01$ & $3.16^{\mathrm{a}} \pm 0.14$ \\
$\mathbf{D}$ & $270.98^{\mathrm{c}} \pm 1,98$ & $4.4^{\mathrm{a}} \pm 0.46$ & $0.21^{\mathrm{a}} \pm 0.06$ & $0.04^{\mathrm{a}} \pm 0.01$ & $3.45^{\mathrm{a}} \pm 0.26$ \\
E & $286.64^{\mathrm{c}} \pm 2.26$ & $4.6^{\mathrm{a}} \pm 0.86$ & $0.22^{\mathrm{a}} \pm 0.04$ & $0.04^{\mathrm{a}} \pm 0.01$ & $3.40^{\mathrm{a}} \pm 0.26$ \\
F & $254.68^{\mathrm{c}} \pm 2.86$ & $4.8^{\mathrm{a}} \pm 0.38$ & $0.23^{\mathrm{a}} \pm 0.06$ & $0.04^{\mathrm{a}} \pm 0.02$ & $3.44^{\mathrm{a}} \pm 0.18$ \\
G & $258.76^{\mathrm{c}} \pm 2.78$ & $5.1^{\mathrm{a}} \pm 0.46$ & $0.24^{\mathrm{a}} \pm 0.02$ & $0.04^{\mathrm{a}} \pm 0.01$ & $3.48^{\mathrm{a}} \pm 0.12$ \\
H & $225.46^{\mathrm{b}} \pm 2.88$ & $6.38^{\mathrm{b}} \pm 0.48$ & $0.27^{\mathrm{a}} \pm 0.04$ & $0.05^{\mathrm{b}} \pm 0.02$ & $4.14^{\mathrm{b}} \pm 0.24$ \\
I & $180.2^{\mathrm{a}} \pm 3.16$ & $6.86^{\mathrm{c}} \pm 0.66$ & $0.33^{\mathrm{b}} \pm 0.06$ & $0.04^{\mathrm{b}} \pm 0.01$ & $4.64^{\mathrm{b}} \pm 0.22$ \\
J & $168.5^{\mathrm{a}} \pm 2.36$ & $6.98^{\mathrm{c}} \pm 0.36$ & $0.34^{\mathrm{b}} \pm 0.08$ & $0.04^{\mathrm{b}} \pm 0.02$ & $4.61^{\mathrm{b}} \pm 0.22$ \\
K & $186.9^{\mathrm{a}} \pm 3.48$ & $7.26^{\mathrm{c}} \pm 0.88$ & $0.36^{\mathrm{b}} \pm 0.04$ & $0.06^{\mathrm{b}} \pm 0.01$ & $4.18^{\mathrm{b}} \pm 0.16$ \\
${ }^{*}$ Cornoil Group & $178.8^{\mathrm{a}} \pm 3.18$ & $6.98^{\mathrm{c}} \pm 0.84$ & $0.34^{\mathrm{b}} \pm 0.02$ & $0.05^{\mathrm{b}} \pm 0.02$ & $3.98^{\mathrm{b}} \pm 0.14$ \\
\hline
\end{tabular}

Data are presented as Mean \pm SEM. *LPO (nM MDA/gm of tissue); SOD (U/mg of Protein); GSH (mM GSH/g of Tissue); GST ( $\mu$ M of CDNB-GSH conjugate/min/mg protein); CAT ( $\mathrm{mM} \mathrm{H}_{2} \mathrm{O}_{2}$ utilized $/ \mathrm{min} / \mathrm{mg}$ or protein). Different letters above the bar indicates significance $(\mathrm{p}<0.05)$ among different groups in the columns. ${ }^{*}$ Cornoil Group was taken as the vehicle control group.

However, with co-feeding with $\alpha$-tocopherol and $\alpha$-tocopherol $+\mathrm{GSH}+\mathrm{HAE}$ significantly $(\mathrm{P}<0.05)$ lowered MDA compared to all other groups of rats. However, this reduction in MDA activity in Group $\mathrm{C}$ to $\mathrm{G}$ was not significant $(\mathrm{P}<0.05)$ compared to Group $\mathrm{B}$ and $\mathrm{H}$. Activities of SOD, GSH, GST and CAT in erythrocytes significantly $(\mathrm{P}<0.05)$ lowered in Group $\mathrm{A}$ and all other groups of ACR and antioxidants; however, the activities of these enzymes potentially and significantly $(\mathrm{P}<0.05)$ improved in erythrocytes of Group B and $\mathrm{H}$ rats co-fed $\alpha$-tocopherol with acrylamide.

\section{Oxidative stress parameters in brain}

Oxidative stress parameters in brain of different groups of rats are outlined in Table 5. Significant $(\mathrm{P}<0.05)$ increase in level of MDA was observed in Group A compared to other groups (Group B to K). Lowest level of MDA was observed in Group I, J and K (control groups). Significant 
$(\mathrm{P}<0.05)$ decrease in MDA production was observed in Group B and Group H compared to all other groups of rats taking antioxidants co-fed along with acrylamide. MDA level significantly lowered in Group $\mathrm{C}$ to $\mathrm{G}$ compared to Group A but was non-significant among Groups $\mathrm{C}$ to $\mathrm{G}$. While evaluating activities of SOD, GSH, GST and CAT in brain showed similar trend and better amelioration was observed in rats co-fed $\alpha$-tocopherol with acrylamide.

\section{Histopathological examination of brain}

Microscopic evaluation of brain sections revealed normal histoarchitecture with uniform distribution of neurons in control groups of rats (Fig. 1D), while in Group A, extensive congestion was observed along with increase in perivascular space and degeneration of neurons (Fig 1A, B \& C). Brain in all groups of rats fed with ACR showed neuronal degeneration showing empty places (possibly due to edema or death of neurons or may be due to degeneration of neurons) (Fig. 1A, B). Along with this, deposition of fibrin in the neutrophil was observed as a predominant change in Group A rats (Fig. 1B). No marked histological improvement was observed even after amelioration with different antioxidants but somehow as a mark of protection, $\alpha$-tocopherol co-fed with ACR shown certain degree of improvement in terms of less degeneration and vacuolations in brain. Venous congestion even was absent in brain of Group B rats (Fig. 1E) and rats receiving all three ameliorating agents (Group H) (Fig. 1F). However, no other groups of rats showed improvement in brain histo-architecture fed with antioxidants and their combinations co-fed with ACR.

ACR and its an ingredient of daily baked diet and its metabolite glycidamide generate free radicals that target different cell compartments resulting in oxidative damage to cellular organelles (Kelaivani et al., 2018). Glycidamide is formed by CYP 2E1 mediated hepatic metabolism, is an epoxide and is highly reactive towards protein and nucleic acid nucleophiles. It is reported to be 100-1000 times more reactive with DNA compared to ACR causing genotoxicity in variety of tissues. Studies have shown that ACR causes cytotoxic and histopathological alterations in living tissues including brain leading to degeneration of neurons and inflammation. (Song et al., 2008) as reported in our study as well. Considering ACR as a potential toxic agent closely associated with daily life and as an agent to cause potential neurotoxicity, strategies are required to study its amelioration and potentially by using antioxidants to minimize oxidative stress associated damage to neurons. Several workers have reported oxidative stress as the mode of neurotoxicity and therefore have suggested use of antioxidants as strategies for amelioration.

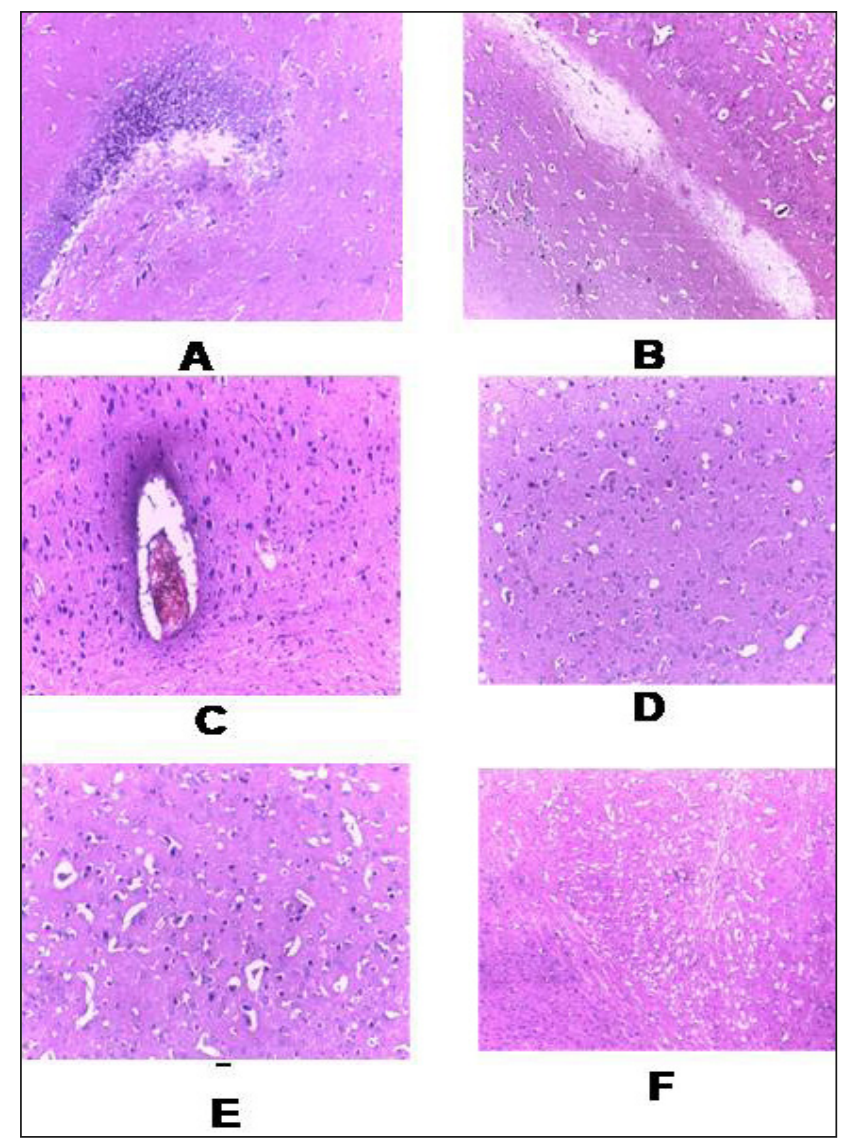

Fig. 1: Photomicrograph showing degeneration of neurons in cerebral cortex of acrylamide fed rats (A) (10x in H \& E Stain); fibrin deposition in degenerated brain areas (20x in $\mathrm{H} \&$ E stain) (B); congestion in blood vessels (20x in H \& E stain) (C) indicating acrylamide mediated neuro degeneration and neurotoxicity; brain section showing normal histoarchitecture of cerebral cortex of control of rats (D) (10x in H \& E stain). $\alpha$ tocopherol co-fed with acrylamide (group B) rat cerebral cortex showing slight neurodegenration and no vascular congestion $(\mathbf{E})$ (10x in $\mathrm{H} \& \mathrm{E}$ stain) and rat cerebral cortex showing low to no neurodegenration in rats co-fed with $\alpha$-tocopherol, GSH and HAE (F) (10x in H \& E stain).

Erythrocyte oxidative parameters are the index of overall antioxidative status of host body and indicate the ability of antioxidant system to protect the host from free radical 
mediated toxicity. Erythrocytes oxidative parameters include LPO, SOD, GSH, GST and CAT which are mostly affected by the oxidant status of the host body (Laborde, 2010). In the present study, erythrocyte MDA levels were significantly increased in Group A rats fed with ACR and along with this, there was significant reduction in all antioxidative enzymes. These findings are the indicators of ACR mediated oxidative stress in Group A rats. On the other hand, MDA levels were significantly low in control groups (Group I, J and K) and enzyme activities were significantly high indicating physiological high antioxidative potential of these groups of rats. Our results were in similar line as reported earlier by various workers regarding ACR mediated oxidative stress to erythrocytes (Halliwell and Gutteridge, 2007). Oxidative stress is a state where an imbalance occurs between reactive oxygen species (ROS) production and their neutralization through antioxidant defense. Increased levels of oxidative damage can result not only from oxidative stress, but also from failure of repair or replacement systems or a rise in levels of biomarkers of oxidative damage (Rehman et al., 2006; Huang et al., 2007).

In the study, ACR compromised the oxidative status of brain as evident from results. Possibly this is one of the mechanisms through which ACR induced neuro degeneration and as it has established that neurodegeneration in brain is irreversible, therefore, in the present study with use of different antioxidants like $\alpha$-tocopherol, GSH and HAE, we did not get significant improvement in brain histology. However, interestingly in the study, brain oxidative stress markers were significantly improved in all supplemented groups compared to ACR fed group indicating ameliorative potential of these compounds from ACR induced toxicity.

Complex structure of neuron and poor to no power of regeneration of neurons are the major factors behind the failure of brain tissue regeneration. ACR induces central, peripheral neurodegeneration, neurodegeneration in thalamus and hippocampus (Friedman and Levin, 2008). Due to acrylamide toxicity, several clinical manifestations are seen like peripheral neuropathy, skeletal muscle weakness, numbness of movement, ataxia and incoordination (CIAA, 2011; Friedman and Levin, 2008). Similar to this, in our study we observed abnormal behavior in ACR fed groups in the form of motor incoordination, ataxia, abnormal gait and poor reflexes.
No studies are cited in literature regarding the protective potential of $\alpha$-tocopherol, GSH and HAE in ameliorating the ACR toxicity. However, numbers of studies have shown the potential roles of antioxidants in reducing the toxic effects of ACR in different organs. We corroborated our findings and compared our results with others reported in ACR induced neurotoxicity using other agents which target the oxidants.

Blue barry anthocyanin extract (BAE) has been shown protective effects and active amelioration from ACR toxicity. BAE inhibited the ACR induced ROS accumulation and glutathione (GSH) depletion, increased activities of glutathione-S-transferase (GST) (Zhang et al., 2015). Silica nano-particles (SNs) of hesperitin (Hst) and naringenin $(\mathrm{Nrg})$ increased the activity of enzymes antioxidants and levels of reduced glutathione, which were lowered in AA-induced neurotoxicity in rats (Lakshmi et al., 2012). These agents also showed neuroprotective effect of the flavanones on ACR induced neurotoxicity by reducing oxidative stress, up-regulating brain antioxidant status, and diminished brain damage (Abo-El-matty et al., 2018).

Significant improvements in oxidative stress biomarkers in brain as well as erythrocytes are the indicators that antioxidants reduce the ACR induced general as well as neurotoxicity. However, the antioxidants used in the study did not completely produce the amelioration and this may be due to the complexity of neurons, or may be due to poor capacity of regeneration of neurons; However, marked improvement was observed in neuro-behavior in rats and which potentially indicated that antioxidants protect the neurotoxicity induced due to ACR.

Ellagic acid showed neuroprotective effects in rats from ACR toxicity by lowering the free radicals generated by ACR. Co-feeding with Ellagic acid improved neuromotor behavior in rats, significantly improved the activities of antioxidative enzymes and lowers the production of MDA (Gourdazi et al., 2019). In another study enrichment with spice active ingredients like Eugenol (EU) and Isoeugenol (IE) showed neuropotection from ACR induced neurotoxicity in Drosophila. The study showed that spice enrichment significantly improved the antioxidant status in Drosophila, reduced the depletion of GSH, and maintained the levels of AchE enzymes and dopamine level in the brain of Drosophila. These protective effects 
of spice were due to their potential ability to target the free radicals generated by ACR (Prasad et al., 2012)

Supplementation with Omega-3 fatty acid showed its ameliorative potential against ACR induced neurotoxicity in rats. Potentially, Omega 3 fatty acid targeted the free radicals generated due to ACR and conferred the neuroprotection indicating its potential antioxidant role. Interestingly, Omega 3 fatty acid also restored the brain levels of GSH indicating its potential role in membrane protection and lower activity of ACR in depleting brain GSH (Elblehi et al., 2020). Similarly, feeding with green tea extract showed potential amelioration in rats from ACR induced neurotoxicity. Green tea contains active ingredients like flavinoids which are potential antioxidants (Panah et al., 2015). Feeding with dark soy sauce showed significant neuro protection in ACR induced neurotoxicity in cerebellum and trigeminal ganglia indicating the potential antioxidant neuroprotective effect of dark soy sauce (Abdelall et al., 2014).

Feeding with Crocin, a proven antioxidant in ACR induced neurotoxic rats showed potential neuro-protection indicating that ACR induces neuro damage potentially through oxidants and these oxidants can effectively neutralized or minimized resulting in decreased oxidative stress and effective neuroprotection (Mehri et al., 2015). Lowering of MDA level along with significant improvement in antioxidant enzymes were the indicators of neuro protective role of Crocin during ACR induced cytotoxicity.

Fish oil supplementation reversed the effects of ACR in rats and offered potential neuro protection from ACR induced neurotoxicity. Fish oil minimized the oxidative stress induced by ACR in rat brain and overall improves the structural and functional aspects of brain (Laxmi et al., 2012). Considering the above pioneer studies in animal models potentially indicate that ACR causes neural damage through oxidative stress. The generated free radicals are potential in lowering the antioxidant defense of host and therefore results in oxidative stress. Therefore, ACR induced neurotoxicity can be effectively managed by using antioxidants.

The current study reveals that $\alpha$-tocopherol and HAE were effective in attenuating ACR-induced neurotoxicity in comparison to reduced gluthathione as $\alpha$ - tocopherol, is a fat-soluble antioxidant that stops the production of
ROS formed when fat undergoes oxidation as well as it could decrease oxidative stress via reducing the level of MDA and increasing the levels of antioxidative enzymes. Therefore, from the results of the study, it is apparent that, these antioxidants can be used for neuro-protection during ACR induced neural toxicity. Also, $\alpha$-tocopherol and HAE increased the capacity of endogenous antioxidant system such as CAT, SOD activity as well as GST level. Therefore, our results suggest that $\alpha$-tocopherol provides the best and safe treatment for the prevention of ACR-induced neurotoxicity in comparison to reduced glutathione and HAE.

In the study, we observed promising roles of $\alpha$-tocopherol, GSH and HAE in offering protection to neurons from acrylamide induced toxicity. Inspite of improvement in oxidative stress parameters and antioxidant enzyme activities, we did not obtain marked improvement in brain histopathology. More evidently, all the abnormal neurophysiological behavior in rats were reversed acrylamide co-fed with antioxidants. More studies are warranted to understand the precise role of these ameliorating agents in offering protection to brain from acrylamide damage.

\section{CONCLUSION}

Although brain histopathology did not show any significant restoration of brain structure in ACR toxicity group, however, feeding with $\alpha$-tocopherol, GSH and HAE significantly decreased the oxidative stress as evident from lower MDA levels and higher activities of antioxidative enzymes. Surprisingly, this degree of amelioration was not observed in rats fed with combination of antioxidants. Significant improvement in antioxidative defense in rats indicated the ameliorative potential of $\alpha$-tocopherol from ACR toxicity and cane be suitably used for neuroprotection from ACR.

\section{ACKNOWLEDGEMENTS}

Authors also thank the Vice Chancellor, U.P. Pt. Deen Dayal Upadhyaya Pashu Chikitsa Vigyan Vishwavidyalaya, Mathura-281001, Dean, College of Veterinary Sciences and Dean, College of Biotechnology for providing necessary facilities to carry out this work. The authors are also thankful to the In-charge Department of Veterinary 
Pathology to carryout histopathological examination of tissues.

\section{CONFLICT OF INTEREST}

The authors declare no conflict of interest with any people or organizations in any financial or personal relationship.

\section{REFERENCES}

Abo-El-matty, D.M., Rizk, M.K., Aly, H.F., Abd-Alla, H.L., Saleh, S.M. and Younis, E.A. 2018. Role of fruit waste and flavanones-loaded silica nanoparticles in ameliorating oxidative stress and histological changes in rat brain induced by acrylamide. J. Mater. Env. Sci., 6: 1817-1828.

Ahmed, R.S.; Seth, V., Pasha, S.T. and Banerjee, B.D. 2000. Influence of dietary Ginger (Zingiber officinales Rosc) on oxidative stress induced by malathion in rats. Food. Chem. Toxicol., 38: 443- 450.

Bergmeyer, H.U., 1983. U.V. method of catalase assay. In: Methods of enzymatic analysis, III $3^{\text {rd }}$ Ed. Weinheim, Dacrfield Beach, Florida, Basal. 273.

Chen, J.H. and Chou, C.C. 2015. Acrylamide inhibits cellular differentiation of human neuroblastoma and glioblastoma cells. Food. Chem. Toxicol., 82: 27-35.

CIAA. 2011. The CIAA acrylamide toolbox. Confederation of the European Food and Drink Industries (CIAA), Brussels.

Esmaeelpanah E., Rahmatkhah A., Poormahmood N., Razavi MB., Hasani FV. and Zadeh HH. 2015. Protective effects of Green tea aqueous extract on acrylamide induced neurotoxicity. J.Nat.Pharm.Prod., 10(2): e18506.

Gupta A,. 2009. Studies on antibacterial and antiviral properties of Ocimum sanctum leaves with reference to immunomodulatory effects in rats. MVSc Thesis submitted to U.P. Pandit Deendayal Upadhayaya Pashu Chikitsa Vigyan Vishwavidyalaya Evam Go Anusandhan Sansthan, Mathura, U.P, India.

Habig, W.H., Pabst, M. J. and Jakoby, W.B. 1974. GlutathioneS-transferase: the first enzymatic step in mercapturic acid formation. J. Biol. Chem., 249: 7130-7139.

Halliwell, B. and Gutteridge, J.M.C. 2007. Free radicals in biology and medicine, $4^{\text {th }}$ Edn, Clarendon Press, Oxford.

Huang, Y.L., Yu, F.Z., Si, Y.W. and Shi, N. 2007. NF-E2 related factor 2 activation and hemeoxygenase- 1 induction by tertbutylhydroquinone protect against deltamethrin-mediated oxidative stress in PC12 cells. Chem. Res. Toxicol., 20: 12421251

Keramat, J., Lebail, A., Prost, C. and Jafari, M. 2011. Acrylamide in baking products: a review article. Food Biopro. Tech., 4: 530-543.
Kumar, J., Das, S. andTeoh, Lin S. 2018. Dietary acrylamide and the risks of developing cancer: Facts to Ponder. Front. Nutri., 5: 14.

Laborde, E. 2010. Glutathione transferases as mediators of signaling pathways involved in cell proliferation and cell death. Cell. Death. Differ., 45: 67-98.

Lowery, O.H., Rosenbrough, N.J., Farr, A.L., Randall, R.J., 1951. Protein measurement with the Folin phenol reagent. $J$. Biol. Chem., 193: 265-275.

Luna, L. G., 1968. Manual of histology staining methods of the Armed Forces Institute of Pathology, $3^{\text {rd }}$ edn. Mcgraw-Hill Book Co., New-York.

Madesh, M., and Balasubramanian, A. K., 1998. Microtiter plate assay for superoxide dismutase using MTT reduction by superoxide. Ind. J. Biochem. Biophys., 35:184-188.

Mandil, R., Rahal, A., Prakash, A., Garg, S.K., Gangwar, N.K., Swain, D.K., 2016. Ameliorative potential of alphatocopherol against flubendiamide and copper-induced testicular-injury in Wistar rats. Chem. Biol. Interact., 260: 91-10.

Mehdi, G., Mombeini MA., Fatemi I., Aminzadeh A., Kalantari H., Nesari A., Najafzadehvarzi H., Mehrzadi S.2019. Neuroprotective effects of Ellagic acid gainst acrylamide induced neurotoxiciry in rats. Neuro. Res., 1743-1328.

Mehri S., Abnous K., Khooei A., Mousavi SH., Shariaty MV., Hosseinzadeh H. 2015. Crocin reduced acrylamide induced neurotoxicity in wistar rats through inhibition of oxidative stress. Iran. J. Basic Med. Sci., 18(9): 902-908.

Paglia, D.E., Valantine, W.N., 1967. Studies on the quantitative and qualitative characterization of erythrocyte glutathione peroxidase. J. Lab. Clin. Med., 70: 158-169.

Rehman, H., Ali, M., Atif, F., Kaur, M., Bhatia, K. and Raisuddin, S. 2006. The modulatory effect of deltamethrin on antioxidants in mice. Clin. Chim. Acta., 369: 61-65.

Samar S Elblehi., Omnia I. El Euony., Yasser S. El-Sayed. 2020. Apoptosis and astrogliosis perturbations and expressions of regulatory inflammatory factors and neurotransmitters in acrylamide induced neurotoxicity under $\Omega$ fatty acids protections in rats. Neurtoxicology, 76: 44-57.

Sedlak, J. and Lindsay, R.H. 1968. Estimation of total protein bound NPSH groups in tissues with Ellaman's reagent. Anal. Biochem., 25: 192-205.

Shafiq-U-Rehman. 1984. Lead-induced regional lipid peroxidation in brain. Toxicol. Lett., 21: 333-337.

Sinomol George K., Sunitha, S., Pankaj Satapathy, Ishtaparan Sahoo and Farhan Zameer. 2019. Acrylamide induced toxicity and the propensity of phytochemicals in amelioration: A Review. Cen. Nerv. Sys. Med. Chem., 19: 1-14. 
Song, HX., Wang, R., Geng, ZM., Cao, SX., Liu, TZ., 2008. Subchronic exposure to acrylamide affect reproduction and testis endocrine function of rats. Zhanghua. Nan. Ke. Xue., 14: 406-410.

Surdyk, N., Rose,'N.J., Andersson, R. and Aman, P. 2004. Effects of asparagine, fructose, and baking conditions on acrylamide content in yeast-leavened wheat bread. J. Agric. Food. Chem., 52: 2047-2051.

Tredici, G., Cavaletti, G., Petruccioli, M.G., Fbbrica, D., Tedeschi, M. and Venturino, P. 1994. Low-dose glutathione administration in the prevention of cisplatin-induced peripheral neuropathy in rats. Neurotoxicology, 15(3): 701-4.
Yagi, K. 1989. A simple fluorimetric assay for lipid peroxides in blood serum or plasma. In: CRC Handbook of Free Radicals and Antioxidants in Biomedicine, 3: 215-218.

Zhang, L. Zhang, G. and Zhang, Y. 2005. Occurrence and analytical methods of acrylamide in heat treated foods: Review and recent developments. J. Chromatography, 1075: $1-21$.

Zhang, Y., Liu, M., Tan, D., Tong, C., Xu, Y., Liu, X., Gao, Y. and Hou, M. 2015. Blueberry anthocyanins ameliorate radiationinduced lung injury through the protein kinase RNA activated pathway. Chemico-Bio. Interact., 242: 363-371. 